\title{
The Relationship between Mental Health and Depression among Science Faulty Students
}

\author{
Dr. R.R. Shinde ${ }^{1 *}$
}

\section{ABSTRACT}

Objective of the study: To find out the relationship among depression on mental health among science faculty students. Hypotheses: 1. Low depress college students will significantly high mental health than the high depress science faculty students. 2. There will be negative correlationship between mental health and depression among science faculty students. Sample: The effective sample consisted of 80 subjects, among 40 subjects were Low depress and 40 subjects were high depress science faculty students from Aurangabad (Maharashtra). The age range of subjects where 20-24 years (Mean 20.75, SD 3.26). And Simple random sampling was used. Variable: Independent variable- Depression a) High b) Low Dependent Variable: Mental Health Tools: Mental Health Inventory (MHI): Mental health inventory constructed by Dr. Jagdish and Dr. A K Srivastav. 2. Depression Scale: Depression Scale construct by Dr. Shamim Karim and Dr. Rama tiwari. Conclusions: 1.Low depresses science faculty students had significantly high mental health than the high depress science faculty students. 2. Negative Correlation between depression and mental health among science faculty students.

Keywords: Mental Health, Depression, Science Faulty Students

The quality of our lives depends upon the quality of our relationships with others. Relationships are the source of so much of our happiness and success, but they can also be the cause of our pain and despair. And when we have problems with our primary relationships, it's difficult to find joy in anything else.

Problems and misfortunes are a part of life. Everyone experiences unhappiness, and many people may become depressed temporarily when things don't go as they would like. Experiences of failure commonly result in temporary feelings of worthlessness and self-blame, while personal losses cause feelings of sadness, disappointment and emptiness. Such feelings are normal, and they usually pass after a short time. This is not the case with depressive illness. Depression is

\footnotetext{
${ }^{1}$ Assit. Professor in Psychology, Vivekanad Art’s, Sardar Dalipsing Commerce and Science College, Aurangabad, India

*Responding Author

(c) 2016 Shinde R; licensee IJIP. This is an Open Access Research distributed under the terms of the Creative Commons Attribution License (http://creativecommons.org/licenses/by/2.0), which permits unrestricted use, distribution, and reproduction in any Medium, provided the original work is properly cited.
} 
The Relationship between Mental Health and Depression among Science Faulty Students

different from feeling down or sad. Unhappiness is something which everyone feels at one time or another, usually due to a particular cause. A person suffering from depression will experience intense emotions of anxiety, hopelessness, negativity and helplessness, and the feelings stay with them instead of going away. Depression can happen to anyone. Many successful and famous people who seem to have everything going for them battle with this problem. Depression also affects people of every age. Half of the people who have depression will only experience it once but for the other half it will happen again. The length of time that it takes to recover ranges from around six months to a year or more. Living with depression is difficult for those who suffer from it and for their family, friends, and colleagues. It can be difficult to know if you are depressed and what you can do about it.

\section{Types of depression}

There are several types of depression, some of which are listed below.

\section{- Mild depression}

Depression is described as mild when it has a limited negative effect on your daily life. For example, you may have difficulty concentrating at work or motivating yourself to do the things you normally enjoy.

\section{- Major depression}

Major depression interferes with an individual's daily life - with eating, sleeping and other everyday activities. Some people may experience only one episode but it is more common to experience several episodes in a lifetime. It can lead to hospital admission, if the person is so unwell they are at risk of harm to themselves.

\section{- Bi-polar disorder}

The mood swings in bi-polar disorder can be extreme - from highs, where the individual feels extremely elated and indestructible, to lows, where they may experience complete despair, lethargy and suicidal feelings. Sometimes people have very severe symptoms where they cannot make sense of their world and do things that seem odd or illogical.

\section{- Post-natal depression}

Many new mothers experience what are sometimes called 'baby blues' a few days after the birth. These feelings of anxiety and lack of confidence are very distressing but in most cases last only a couple of weeks. Post-natal depression is more intense and lasts longer. It can leave new mothers feeling completely overwhelmed, inadequate and unable to cope.

Fosterling and Binser (2002) investigated the link between depression and school performance among high school students. High depression scores were associated with low overall grades. The authors found that pupils with low grades and pupils who are depressed attributed failure to internal, stable and global causes more than high achievers and non-depressed pupils did. These findings demonstrated the vicious cycle that exists between depression and low grades, creating a downward spiral towards worsening mental health and failing grades. 
The Relationship between Mental Health and Depression among Science Faulty Students

David M. Fergusson; Lianne J. Woodward, (March 2002) Mental Health, Educational, and Social Role Outcomes of Adolescents with Depression. Background This study used longitudinal data to examine the extent to which young people with depression in mid adolescence (ages 14-16) were at increased risk of adverse psychosocial outcomes in later adolescence and young adulthood (ages 16-21). Methods Data were gathered during a 21-year longitudinal study of a birth cohort of 1265 children. Measures included assessments of DSM-III$R$ major depression (at age 14-16); psychiatric disorders, educational achievement, and social functioning (at age 16-21); social, familial, and individual factors; and comorbid disorders. Results Thirteen percent of the cohort developed depression between ages 14 and 16. Young people with depression in adolescence were at significantly $(P<.05)$ increased risk of later major depression, anxiety disorders, nicotine dependence, alcohol abuse or dependence, suicide attempt, educational underachievement, unemployment, and early parenthood. These associations were similar for girls and boys. The results suggested the presence of 2 major pathways linking early depression to later outcomes. First, there was a direct linkage between early depression and increased risk of later major depression or anxiety disorders. Second, the associations between early depression and other outcomes were explained by the presence of confounding social, familial, and individual factors. Conclusions Young people having early depression were at increased risk of later adverse psychosocial outcomes. There was a direct linkage in which early depression was associated with increased risk of later major depression and anxiety disorders. Linkages between early depression and other outcomes appeared to reflect the effects of confounding factors.

Maximus (2001) studied Depression and Other Mental Health Barriers among Welfare Recipients. It was conducted with more than 3,400 welfare recipients in the age range of 18-61 .Study was based on telephone surveys in three states: New Mexico, North Carolina, and California (San Bernardino County) Results showed that depression varied considerably by age group. Older recipients were more likely than younger recipients to have experienced depression during the past year. Of the respondents aged 40 and older, between 57 and 61 percent reported experiencing problems with depression.

\section{METHOD}

Objective of the study:

- To find out the effect of depression on mental health of college students.

\section{Hypotheses:}

1. Low depress college students have significantly high mental health than the high depress college students.

2. There will be negative correlationship between mental health and depression among college students. 
The Relationship between Mental Health and Depression among Science Faulty Students

\section{Sample:}

The effective sample consisted of 80 subjects, out of which 40 subjects were Low depresses and 40 subjects were high depress of College of Aurangabad (Maharashtra). The age range of subjects where 18-25 years (Mean 20.36, SD 3.45). And Non- probability accidental and purposive sampling was used.

\section{Variable}

Independent variable-

Depression: a) High b) Low

Dependent Variable: Mental Health

\section{Tools:}

1) Mental Health Inventory (MHI):

Mental health inventory constructed by Dr. Jagdish and Dr. A K Srivastav. 56 items are in the questionnaire and each of the items has four responses -1 . Almost always true, 2 . Some time true, 3. Rarely true and 4 . Almost never true. The reliability of the inventory was determined by split-half method using odd-even procedure. Overall mental health reliability coefficients is .73 and Construct validity of the inventory is determined by finding coefficient of correlation between scores on mental health inventory and general health questionnaire (Gold beig, 1978) it was found to be .54 .

\section{2) Depression Scale:}

Depression Scale construct by Dr. Shamim Karim and Dr. Rama tiwari. All the 96 items of the scale. And each of the item has two answer (multiple Choice) 'YES' and 'NO' split-half reliability, Guttman and spearman-Brown's prophency formula have been used which yielded the coefficient of correlation as +.86 and +.92 respectively, when this test was administered on a sample of 100 subjects. and factor analysis method used for validity.

\section{Procedures of data collection:}

The study was conducted in two phases. In the first phase, depression test were give on the 150 college students. The data were obtained and median value on depression test was calculated. Students at and above median value were treated as having Low depress College students and below median value were treated as having high depress College students. From among 80 students, 40 students having Low depress students and 40 students having high depress, were selected. The selected students were subjected to mental health Inventory in the second phase. The obtained data analyzed using t-test. 
The Relationship between Mental Health and Depression among Science Faulty Students

STATISTICAL ANALYSIS AND DISCUSSION

High depress college student and low depress college student, Shows the mean S.D and $t$ value of mental health

\begin{tabular}{|l|c|c|c|c|c|c|c|c|c|}
\hline \multirow{2}{*}{ Dimension } & \multicolumn{3}{|c|}{$\begin{array}{c}\text { High Depress Students } \\
\text { (N=40) }\end{array}$} & \multicolumn{3}{|c|}{$\begin{array}{c}\text { Low Depress } \\
\text { Students (N=40) }\end{array}$} & \multirow{2}{*}{ t- ratio } & \multirow{2}{*}{ df } & \multirow{2}{*}{ p } \\
\cline { 2 - 9 } & Mean & SD & SE & Mean & SD & SE & & & \\
\hline Mental Health & 152.75 & 14.43 & 1.97 & 184.02 & 16.39 & 1.75 & 14.10 & 78 & $<.01$ \\
\hline
\end{tabular}

The results related to the hypothesis have been recorded. Mean of Total Mental Health score of the high depress College Students Mean is 152.75 and that of the low depress College Students Mean is 184.02 The difference between the two mean is highly significant (' $\mathrm{t}$ '= 14.10 , $\mathrm{df}=78, \mathrm{P}$ $<0.01$ ) This Result Support the Hypothesis. Low depress college students have significantly high mental health than the high depress college students. A similar finding was reported earlier by David M. Fergusson, and others (March 2002) Mental Health, Educational, and Social Role Outcomes of Adolescents with Depression. Conclusions Young people having early depression were at increased risk of later adverse psychosocial outcomes. There was a direct linkage in which early depression was associated with increased risk of later major depression and anxiety disorders. Linkages between early depression and other outcomes appeared to reflect the effects of confounding factors.

Table No. 02, ' $r$ ' showing the significance of relationship between mental health and depression among college students

\begin{tabular}{|lcccc|}
\hline Dimensions & N & r & DF & P \\
\hline $\begin{array}{l}\text { Depression } \\
\text { Mental Health }\end{array}$ & 80 & -.453 & 78 & .01 \\
\hline
\end{tabular}

The results displayed in table 02 clearly indicated the significant relation between depression and mental health. The correlation of depression and mental health and significant $(r=-0.46$, $\mathrm{df}=78$, $\mathrm{P}<.01)$.

In some studies it has been found that higher intelligence scores were associated with lower depression scores, better mental health (Dulewicz and Slashi, 2003; Montes-Berges and Augusto, 2007; Kumar et al., 2007; Gale and Batty, 2009; Gupta and Kumar, 2010).

\section{CONCLUSIONS}

1. Low depress college students have significantly high mental health than the high depress college students.

2. Negative Correlation between depression and mental health among college students 
The Relationship between Mental Health and Depression among Science Faulty Students

\section{Acknowledgments}

The author appreciates all those who participated in the study and helped to facilitate the research process.

\section{Conflict of Interests}

The author declared no conflict of interests.

\section{REFERENCES}

David M. Fergusson, PhD; Lianne J. Woodward, PhD (March 2002) Mental Health, Educational, and Social Role Outcomes of Adolescents With Depression. Arch Gen Psychiatry. Vol. 59 No. 3, March 2002;59:225-231.

Dulewicz, V and Slaski, M. (2003). Measuring emotional intelligence, content, construct, and criterion related validity. Journal of Managerial Psychology, 18(5), 405-420.

Försterling, F., \& Binser, M. J. (2002). Depression, school performance, and the veridicality of perceived grades and causal attributions. Personality and Social Psychology Bulletin, 28(10), 1441-1449.

Gale, C.R. and Batty, G.D. (2009) Psychomotor Coordination and Intelligence in Childhood and Health in Adulthood. Psychosomatic Medicine, 71(6), 675-681.

Gupta, G. and Kumar, S. (2010) Mental Health in Relation to Emotional Intelligence and Self Efficacy among College Students. Journal of the Indian Academy of Applied Psychology, 36(1), 61-67.

J.A.C. Brown, The Social Psychology of Industry (Baltimore, Md.: Penguin, 1954), pp. 253-54.

Johns Hopkins University. (2007). Origins of Mental Health. Retrieved June 1, 2007.

Keyes, Corey (2002). "The mental health continuum: from languishing to flourishing in life". Journal of Health and Social Behaviour 43: 207-222.

Kumar, D., Sharma, V. and Singh, T.B. (2007) A Study of Mental Health among Customer Care Executives in Call Centre‘s. Amity Journal of Behavioural and Forensic Sciences, 3(2).

MAXIMUS (2001)., Depression and Other Mental Health Barriers Among Welfare Recipients Results from Three States Background.

Montes-Berges, B., Augusto-Landa, J.M., 2007. Exploring the relationship between perceived emotional intelligence, coping social support and mental health in nursing students. Journal of Psychiatric and Mental Health Nursing 14, 163-171.

Office of the Deputy Prime Minister - Social Exclusion Unit: "Factsheet 1: Stigma and Discrimination on Mental Health Grounds".2004.

Weare, Katherine (2000). Promoting mental, emotional and social health: A whole school approach. London: Routledge Falmer. p. 12.

Witmer, J.M.; Sweeny, T.J. (1992). "A holistic model for wellness and prevention over the lifespan". Journal of Counseling and Development 71: 140-148.

World Health Report 2001 - Mental Health: New Understanding, New Hope, World Health Organization, 2001.

How to cite this article: Shinde R (2016), The Relationship between Mental Health and Depression among Science Faulty Students, International Journal of Indian Psychology, Volume 4, Issue 1, No. 81, ISSN:2348-5396 (e), ISSN:2349-3429 (p), DIP:18.01.127/20160401, ISBN:978-1-365-59365-9 